\title{
Repercussões clínicas e terapêuticas da COVID-19 em portadores de doenças reumáticas
}

\author{
Clinical and therapeutic repercussions of COVID-19 in patients with rheumatic diseases \\ Repercusiones clínicas y terapéuticas de COVID-19 en portadores de enfermedades \\ reumáticas
}

Luana Fernandes da Silva Oliveira Castro ${ }^{1 *}$, Lorena Sipauba Pitanga ${ }^{1}$, Fernanda Rodrigues Mangabeira Fernandes ${ }^{1}$, Maria Letícia Lopes Mol Caselato1, Juliano Passos Barbosa1, Letícia Dutra Magalhães Vinhal $^{1}$, Renan Vezolle Rocha ${ }^{1}$, Ellen de Lima Rocha ${ }^{1}$, Leonardo Martins Parca ${ }^{1}$, Eliana Teles de Gois ${ }^{2}$.

\section{RESUMO}

Objetivo: Analisar as repercussões clínicas e terapêuticas em portadores de doença reumática diante a coinfecção por SARS-CoV-2. Revisão bibliográfica: O surgimento do SARS-CoV-2 em dezembro de 2019 gerou uma mobilização internacional da comunidade científica a fim de elucidar repercussões clínicas e farmacológicas da COVID-19. Em portadores de doenças reumáticas, apesar de lesão tecidual relacionada a um estado de hiperinflamação do organismo pela COVID-19, estes apresentam um amplo espectro de disfunção imunológica, tornando a gravidade desta infecção altamente variável e potencialmente de maior risco. Esta condição determina certo desafio, visto que infecções graves são formalmente conhecidas como causa de mortalidade em diversas condições reumáticas. Considerações finais: A revisão visa auxiliar a prevenir complicações e ampliar a segurança aos portadores de doenças reumáticas que, apesar de dados majoritariamente preliminares e observacionais, corroboram com um desfecho favorável embora algumas observações acerca do tratamento devem ser salientadas além de seus potenciais fatores de risco.

Palavras-chave: Doenças reumáticas, COVID-19, Vacinas.

\begin{abstract}
Objective: To analyze clinical and therapeutic repercussions in patients with rheumatic diseases facing SARS-CoV-2 coinfection. Bibliographic review: The emergence of SARS-CoV-2 in December 2019 generated an international mobilization of the scientific community in order to elucidate clinical and pharmacological repercussions of COVID-19. In carriers of rheumatic diseases, despite tissue injury related to a state of hyperinflammation in the body triggered by COVID19 , they present a broad spectrum of immune dysfunction, making the severity of this infection highly variable and potentially at greater risk. This condition poses a certain challenge, since severe infections are formally known to be a cause of mortality in several rheumatic conditions. Final considerations: The literature aims to prevent complications and ensure safety for patients with rheumatic diseases, which, despite mostly preliminary and observational data, generally corroborate a favorable outcome although some observations about treatment should be emphasized in addition to its potential risk factors.
\end{abstract}

Keywords: Rheumatic diseases, COVID-19, Vaccines.

\section{RESUMEN}

Objetivo: Analizar repercusiones clínicas y terapéuticas en pacientes con enfermedades reumáticas frente a la coinfección por SARS-CoV-2. Revisión bibliográfica: La aparición del SARS-CoV-2 en 2019 generó una movilización internacional para dilucidar las repercusiones clínicas y farmacológicas del COVID-19. En los portadores de enfermedades reumáticas, a pesar de la lesión tisular y estado de hiperinflamación del organismo mediante la COVID-19, presentan un amplio espectro de disfunción inmunitaria, lo que hace que la gravedad de esta infección sea muy variable y potencialmente de mayor riesgo. Esta afección plantea un desafío, ya que se sabe que las infecciones graves causan mortalidad en varias afecciones reumáticas. Consideraciones finales: La literatura objectiva prevenir las complicaciones y garantizar la seguridad a los pacientes reumáticos que, a pesar de ser en su mayoría datos preliminares y observacionales, generalmente corroboran con un resultado favorable, aunque se deben destacar algunas observaciones sobre el tratamiento y potenciales factores de riesgo.

Palabras clave: Enfermedades reumáticas, COVID-19, Vacunas.

${ }^{1}$ Centro Universitário do Planalto Central Apparecido dos Santos (UNICEPLAC), Brasília - DF.

*E-mail: luanafernandes2000@gmail.com

2 Secretaria de Saúde do Distrito Federal (SES-DF), Brasília - DF. 


\section{INTRODUÇÃO}

A pandemia causada pelo Coronavírus da Síndrome Respiratória Aguda Grave 2 (SARS-CoV-2), descoberto em dezembro de 2019 em Wuhan, levou a grandes perturbações em quase todos os aspectos da saúde em todo o mundo. A morbimortalidade atribuída à doença teve um impacto importante sobre a saúde e a prestação de cuidados de saúde (ZHU N, et al., 2020; CURTIS JR, et al., 2021).

A gravidade do Novo Coronavírus (COVID-19) é altamente variável, caracterizada por uma infecção viral respiratória aguda seguida por hiperinflamação e, em um subconjunto de pacientes, evoluindo com doença grave. Conforme o curso da infecção por SARS-CoV-2 progride, a doença pode ser autolimitada ou evoluir para a necessidade de oxigênio suplementar e hospitalização, normalmente 7-10 dias após o início dos sintomas. Nesses casos a doença é caracterizada por hipóxia, mas o envolvimento de outros sistemas e órgãos pode ocorrer. Essa desregulação imunológica é caracterizada por linfocitopenia, níveis elevados de citocinas plasmáticas e de células T proliferativas. (GOLDMAN JD, et al., 2021; CHENG C, et al., 2020).

De acordo com dados obtidos pela Chinese Center for Disease Control and Prevention sobre fatores de risco clínicos para apresentações mais graves da doença, a idade é um fator preditivo exponencial de mortalidade. Ademais, a presença de marcadores inflamatórios foi mais fortemente associada com mau prognóstico. Comorbidades clínicas incluindo diabetes, hipertensão arterial, doença renal crônica, obesidade, câncer e imunossupressão, também estão associadas à progressão da doença e morte em estudos retrospectivos (GOLDMAN JD, et al., 2021; WANG Q, et al., 2021).

Pacientes com doenças reumáticas apresentam um amplo espectro de disfunção imunológica, englobando doenças inflamatórias, como artrite reumatoide, doenças do tecido conjuntivo (lúpus eritematoso sistêmico e vasculite sistêmica) como arterite de células gigantes. Essas são causadas por mecanismos mediados por células e por anticorpos, com imunodeficiência coexistente. Devido a desregulação do sistema imunitário, tratamento imunossupressor e comorbidades concomitantes, os indivíduos com doença reumática inflamatória têm um risco aumentado de infecção (BATIBAY S, et al., 2021; GOLDMAN JD, et al., 2021).

Portanto, esta revisão buscou elucidar os potenciais fatores de risco da COVID-19 a portadores de doenças reumáticas e auxilia-los a prevenir complicações e ampliar a segurança durante o tratamento e prognóstico desta condição.

\section{REVISÃO BIBLIOGRÁFICA}

\section{Doenças Reumáticas e seus Fatores de Risco Frente à COVID-19}

Os portadores de Doença Reumática Imunomediada (DRIM) possuem disfunção imunitária e estão frequentemente em terapia com glicocorticoides e/ou imunossupressores, o que predispõe a um risco aumentado de contrair uma infecção, visto que ambas as condições se sobrepõem. Se esse risco aumentado se traduz para COVID-19 ainda não está claro, pois a maior parte da literatura publicada é observacional e poucos estudos descreveram a presença concomitante de COVID-19 em doentes com doenças reumáticas. No entanto, em surtos de coronavírus anteriores, os pacientes com DR não apresentavam risco aumentado de complicações graves (CHENG C, et al., 2020; FITZGERALD GE, et al., 2021; WANG Q, et al., 2021).

O primeiro relatório publicado sobre a COVID-19 em portadores de doenças reumáticas sugeriu que não haveria maior risco em relação à população geral ou com outras comorbidades. Desde então, alguns estudos abordaram o risco e gravidade da infecção por COVID-19 em pessoas com doença reumatológica imunomediada, confirmando esta impressão inicial, exceto no caso de hospitalização em doentes expostos a doses elevadas de glicocorticóides. Neste caso, em um cenário de maior gravidade, os portadores de DRIM são mais susceptíveis a progredir para COVID-19 crítica (MARQUES CDL, et al., 2021).

Porém, um risco reduzido de hospitalização foi observado em pacientes com o uso de medicamentos antirreumáticos modificadores da doença, ou seja, sem terapias biológicas anticitocinas ou inibidores de JAK (Janus quinase). Esse risco reduzido de hospitalização foi em grande parte impulsionado por inibidores de TNF, que diminuíram as chances de hospitalização quando usados como monoterapia (GOLDMAN JD, et al., 2021; WANG Q, et al., 2021). 
Não há atualmente nenhuma evidência convincente que identifique um risco maior de infecção por COVID19 grave na população com doença reumática. Porém, pulsoterapia com metilprednisolona e/ou ciclofosfamida são condições frequentemente presentes em pacientes com doença reumática que podem predispor maior vulnerabilidade às infecções virais (MIKUS TR, et al., 2020; GOLDMAN JD, et al., 2021; WANG Q, et al., 2021; MARQUES CDL, et al., 2021).

\section{COVID-19: Recomendações Clínicas e Medidas Preventivas para Portadores de Doenças Reumáticas}

As recomendações clínicas sugerem que os pacientes com DRIM devem fortalecer sua própria proteção a fim de evitar a exposição ao SARS-CoV-2 devendo permanecer seguindo as diretrizes de saúde. Desse modo, estratégias preventivas não farmacológicas são bem-vindas. Dentre elas, estão o distanciamento social, a não realização de eventos e de outros tipos de aglomerações, restrição de transportes públicos e de circulação nas ruas, exceto para a aquisição de insumos do gênero alimentício e medicamentoso ou a busca de assistência à saúde. $O$ isolamento de infectados, a constante higienização das mãos e o uso adequado de máscara são os meios mais eficazes de prevenção (WANG Q, et al., 2021; CORRÊA MCDV, et al., 2020; AQUINO EML, et al., 2020; CDC, 2021).

No que se refere à vacinação, a Sociedade Brasileira de Reumatologia (SBR), em junho de 2021, esclareceu que a população de DRIM, incluindo portadores de espondiloartrites, artrite reumatoide, lúpus eritematoso sistêmico, esclerodermia e miopatias inflamatórias não representam uma contraindicação para receber qualquer vacina disponível contra a COVID-19. Portanto, mesmo para pacientes em tratamento com imunossupressores, recomenda-se a busca pela vacina. Ainda assim, mesmo que não contraindicado, é proposto que os pacientes com DR procurem um reumatologista para melhores orientações individualizadas sobre a vacinação para a COVID-19 (SBR, 2021b).

A Global Rheumatology Alliance (GRA) realizou grande parte dos estudos observacionais que serviram de registro para tal discussão. Nesse sentido, reconhecendo que era primordial reunir o máximo de informação possível em tempo hábil, a Comunidade reumatológica internacional se mobilizou a fim de estabelecer uma coleta, análise e divulgação de informações sobre COVID-19. A análise dos primeiros 600 casos portadores de DR (91\% diagnóstico confirmado) revelou que $46 \%$ da população avaliada foram hospitalizados e $9 \%$ cursaram com desfechos fatais (FITZGERALD GE, et al., 2021).

Nesse contexto, um estudo de coorte comparativo de maior dimensão usando a rede TriNetX dos Estados Unidos da América, uma robusta rede de sistemas de saúde provida de dados e imagens de saúde e atualizações in vivo, incluiu 2379 doentes com doenças reumáticas. Utilizando um score logístico com adequação de pontuação para medidas de proteção e incluindo as variáveis idade, sexo, etnia e índice de massa corporal, defrontaram pequenos aumentos no risco de hospitalização, admissão na unidade de terapia intensiva, insuficiência renal aguda e tromboembolismo venoso (GOLDMAN JD, et al., 2021).

As taxas de mortalidade bruta variam globalmente de 5,6 a $152 \%$, com maior risco de morte para os indivíduos idosos e aqueles com comorbidades associadas, tais como hipertensão e diabetes mellitus. Um prognóstico de 46.248 ocorrências revelou que a hipertensão (17\%, IC 95\% 14-22\%), diabetes mellitus (8\%, IC 95\% 6-11\%), doença cardiovascular (5\%, IC 95\% 4-7\%) e condição respiratória (2\%, IC 95\% 1-3\%) são as comorbilidades mais prevalentes (MISRA DP, et al., 2020).

O peso da evidência até agora não sugere que a imunossupressão esteja associada ao aumento da mortalidade, especialmente nas ocasiões em que os fatores de risco conhecidos (idade e comorbidades) são incluídos nos modelos. A evidência neste ponto é baseada em cuidados retrospectivos, muitos desses registros estão sujeitos a vieses e ao acaso. Tais estudos, portanto, corroboram com a hipótese de que os fatores de risco para desfechos desfavoráveis em pacientes com condição reumática certamente foram mediados por comorbidades prévias e não pela infecção viral propriamente dita (GOLDMAN JD, et al., 2021).

\section{Evidências científicas quanto à eficácia do uso de Drogas Modificadoras do Curso da Doença (DMCD)/DMARD na COVID-19}

Sobre a continuidade do uso de Drogas Modificadoras do Curso da Doença (DMCD) e terapia biológica durante a infecção por SARS-CoV-2, uma pesquisa recente observou que não houve riscos adicionais a 
eventos adversos relacionados à COVID-19. Sendo, os pacientes aconselhados a não interromper o tratamento reumatológico mediante suspeita ou confirmação da infecção viral em discussão (FITZGERALD GE, et al., 2021).

A European Alliance of Associations for Rheumatology (EULAR) recomenda que indivíduos contactantes com caso confirmado de COVID-19 sejam submetidos ao teste. Ademais, sugere que conduta terapêutica de pacientes em uso de DMCD com sintomas leves de COVID-19 devem ser discutidas individualmente. Existe também a recomendação de continuidade do uso de glicocorticoide quando o indivíduo já está em tratamento crônico. Contudo, o American College of Rheumatology (ACR) indica a interrupção dos imunossupressores, inibidores anti-IL-6 e JAKi em indivíduos com COVID-19 documentado ou presuntivo. Além disso, aconselham que a hidroxicloroquina pode ser continuada na maioria das circunstâncias as quais serão discutidas a seguir (FITZGERALD GE, et al., 2021).

A Cloroquina ( $C Q)$ e a Hidroxicloroquina ( $\mathrm{HCQ}$ ) são drogas com potencial utilidade no tratamento de diversas doenças por apresentarem importantes efeitos anti-inflamatórios e imunomoduladores e têm demonstrado seus efeitos farmacológicos no tratamento de doenças autoimunes crônicas. A hidroxicloroquina é utilizada como antimalárico e em doenças reumatológicas. No início da pandemia, havia um interesse considerável nos potenciais benefícios terapêuticos dessas drogas no tratamento do COVID-19, recebendo destaque midiático. Isso teve consequências indesejadas, especialmente para a comunidade reumatológica, devido à restrição ao acesso à $\mathrm{HCQ}$ por aqueles que dela necessitavam para o controle da doença reumática. Essa proposta baseou-se na capacidade da CQ em interromper a replicação do SARS-CoV-2 in vitro e inibir a ligação do SARS ao receptor celular (BRAZÃO SC, et al., 2021; FITZGERALD GE, et al., 2021; BESSIÈR F, et al., 2020).

A promoção inicial intensa sobre a HCQ foi baseada em um estudo pequeno, aberto e não randomizado, com metodologia questionável, que concluiu que a $\mathrm{HCQ}$ e (azitromicina em um pequeno número de pacientes) resultou em eliminação mais rápida do vírus no sexto dia em comparação com os pacientes controles. Apesar da falta de evidências científicas sólidas, resultados iniciais supostamente enviesados influenciaram a introdução da hidroxicloroquina como forma experimental no tratamento da COVID-19 em vários países, conduta amplamente criticada na comunidade científica (FITZGERALD GE, et al., 2021).

Outrossim, o estudo retrospectivo citado por Lebeaux D e Revest M (2020) descreveram o uso combinado de hidroxicloroquina e ivermectina e descobriu que esta associação reduziu o risco de deterioração clínica, hospitalização e morte. No entanto, alguns autores discutem os vieses de seleção induzidos por sua abordagem diagnóstica. $\mathrm{Na}$ análise dessa metodologia, ao oferecer a amostragem por PCR a pacientes ambulatoriais, principalmente adultos, foram selecionados jovens com baixa incidência de comorbidades. Sem um grupo controle, é difícil atribuir esse resultado à sua intervenção terapêutica.

A profilaxia pós-exposição com HCQ também foi avaliada, concluindo-se que a mesma não preveniu a infecção por SARS-CoV-2. A pesquisa examinou dois possíveis efeitos da terapia pós-exposição: profilaxia para contatos com um teste de PCR negativo ou positivo no início do estudo. A HCQ não foi eficaz como terapia profilática em pacientes que tinham PCR negativo ou nos quais o PCR era positivo no início do estudo. A droga também não reduziu a transmissão da SARS-CoV-2 ou a ocorrência de soropositividade (MITJÀ O, et al. 2021).

A toxicidade cardiovascular é a principal preocupação com relação ao uso de $\mathrm{HCQ}$, bem como eventos adversos que são exacerbados quando há coadministração com a azitromicina. Um estudo realizado em pacientes hospitalizados com infecção em estágio leve a moderado não mostrou evidências significativas no estado clínico de grupos que receberam o tratamento proposto. Aqueles que receberam HCQ, isolada ou associada à azitromicina, no período de 15 dias, tiveram eventos recidivos de prolongamento do intervalo QT e elevação nos níveis séricos das enzimas hepáticas (THE RECOVERY COLLABORATIVE GROUP, 2020; MERCURO NJ, et al., 2020; CAVALCANTI AB, et al., 2020).

Outro achado é o tratamento com sulfassalazina (SSZ), o qual foi associado a uma maior chance de desfechos fatais. Os resultados do registro internacional de pacientes com doença inflamatória intestinal e COVID-19 também relataram que o uso de SSZ ou 5-aminossalicilato (5-ASA) está associado a predisposição 
a COVID-19 grave. A SSZ é geralmente abarcada no arsenal terapêutico como tendo baixos efeitos imunossupressores. Pesquisas anteriores apoiam os efeitos imunomoduladores da SSZ ou de seu metabólito 5-ASA em outros vírus de RNA. No entanto, a associação entre SSZ e óbitos relacionados ao COVID-19 não deve ser considerada de maneira definitiva (STRANGFELD A, et al., 2021).

Em comparação com as DMCD sintéticas convencionais, as DMCD biológicas, assim como os inibidores de JAK, trazem um risco maior de infecções bacterianas graves. Os inibidores de JAK também aumentam o risco de reativação de herpes zóster. O baracitinibe demonstrou limitar a penetração de SARS-CoV-2 nas células epiteliais do pulmão em estudos preliminares. Uso desta molécula em combinação com ritonavir e remdesivir é corroborado pelas poucas propriedades de ligação às proteínas e mínimas interações às enzimas do citocromo. Entretanto, apresenta a desvantagem de prejudicar a resposta inata, uma vez que reduz a ação do interferon, considerada chave para controle da replicação viral (LADANI AP, et al., 2020).

\section{Inibidores da ECA e BRA}

Reconhecendo que ACE2 é o receptor celular para SARS-CoV-2, existem preocupações sobre terapias conhecidas por aumentar a expressão de ACE2. A American Heart Association, a American Heart Failure Association e o American College of Cardiology recomendaram que pacientes que receberam esses medicamentos continuem a usar inibidores da ECA ou BRA e considerem as consequências cuidadosamente antes de fazer qualquer alteração nesses tratamentos (MIKUS TR, et al., 2020).

\section{Anti-inflamatórios não esteróides (AINEs)}

Embora, no início da pandemia, houvesse especulações sobre o uso de AINEs e desfechos piores de COVID-19, essa hipótese ainda não foi confirmada. Foram aprovados o uso contínuo e a prescrição dessas drogas quando necessário para reumatismo recém diagnosticado, exceto para descontinuar AINEs em pacientes com manifestações graves de COVID-19, como acometimento renal, cardíaco ou gastrointestinal, os quais predizem mau prognóstico. O consenso sobre a suspensão dos AINEs em situações mais brandas de COVID-19 não é definitivo, pois o uso desses medicamentos pode trazer benefícios terapêuticos antipiréticos e anti-inflamatórios. Alguns autores recomendam o uso de paracetamol como alternativa aos AINES, embora haja evidências de lesão hepática em pacientes infectados (MIKUS TR, et al., 2020).

\section{Glicocorticóides}

Os glicocorticóides têm efeito imunossupressor e são frequentemente usados em pacientes com inflamação e doenças autoimunes. Embora tais medicações sejam frequentemente utilizadas em pacientes com sepse, as evidências existentes não apoiam seu uso para reduzir os efeitos prejudiciais da inflamação pulmonar causada por infecções virais. Dessa forma, acredita-se que o tratamento de pacientes recebendo corticoterapia de longo prazo pode ser recomendado com cautela e a dose deve ser gradualmente reduzida para 5 a $7,5 \mathrm{mg} /$ dia durante a infecção pelo SARS-CoV-2 (MISRA DP, et al., 2020).

Por outro lado, reconhecendo os potenciais riscos associados aos efeitos imunossupressores dos glicocorticóides, os dados emergentes sugerem que suas propriedades anti-inflamatórias podem teoricamente reduzir o impacto da COVID-19, especialmente nos estágios finais da infecção (MIKUS TR, et al., 2020).

Reconhecendo que há controvérsia nas evidências existentes, é endossada a administração contínua de glicocorticóides caso seja evitada a interrupção súbita do tratamento (considerando a possibilidade de inibição do eixo hipotálamo-hipófise-adrenal) e utilizar a menor dose efetiva possível para controlar o reumatismo em curso. O grupo de especialistas também apoia o uso de glicocorticóides em baixas doses quando clinicamente indicado e reconhece que mesmo após a exposição ao SARS-CoV-2, doses mais altas podem ser necessárias no caso de doenças graves com risco de vida (MIKUS TR, et al., 2020).

\section{Recomendações Quanto a Vacinação Contra COVID-19 para Pacientes com Doenças Reumáticas}

Portadores de DRIM sofrem efeitos imunomoduladores provocados por suas doenças subjacentes e pelo tratamento com imunossupressores, aumentando a suscetibilidade à infecção pelo SARS-CoV-2, mesmo 
quando vacinados, já que dados iniciais demonstram uma limitada imunogenicidade das vacinas feitas a partir do RNA mensageiro do vírus (mRNA) nestes pacientes. Os testes mostraram que, apesar da maioria dos pacientes portadores de DRIMs ter reagido à primeira dose da vacina de maneira satisfatória, um subgrupo considerável de pacientes permaneceu sem expressar resposta humoral após a segunda dose do imunizante (CONNOLLY CM, et al., 2021).

A Universidade Johns Hopkins conduziu um estudo analisando 20 pacientes com DRIM que não apresentavam anticorpos neutralizantes contra o SARS-CoV-2. Os participantes do coorte eram, principalmente, mulheres brancas com mediana da idade de 46 anos. Dessas, doze (60\%) receberam PfizerBioNTech e oito (40\%) Moderna mRNA. Múltiplos imunossupressores estavam sendo usados por $90 \%$ das pacientes e 16\% usavam corticosteróides em dose de manutenção (faixa de 2,5 a $55 \mathrm{mg}$ ). O agente biológico mais usado foi o rituximab (55\%), enquanto o agente antirreumático mais usado foi o micofenolato (50\%). Nesse caso em especial, o fator unificante desses pacientes foi o uso de fármacos que alteram a viabilidade dos linfócitos, evidenciando a função crítica das células B imunocompetentes na geração de resposta adequada ao antígeno vacinal e contrapondo às robustas respostas dos anticorpos neutralizantes anti-RBD (do inglês Receptor-Binding Domain) estudadas em outros grupos de pacientes portadores de DRIMs. (CONNOLLY CM, et al., 2021).

Foi proposta a seguinte sistematização para aumentar a eficácia vacinal dos pacientes com DRIM: a remissão clínica para evitar exacerbações da doença prévia; o adiamento da terapia imunossupressora, caso seja possível, até que a vacinação seja concluída; a suspensão de 10 dias antes e após a vacinação de medicamentos inibidores da calcineurina e da JAK, além dos antimetabólicos; a redução de doses de prednisona $(>0,5 \mathrm{mg} / \mathrm{kg}$ de peso corporal) ou um esteroide sintético equivalente para $<10 \mathrm{mg} / \mathrm{dia}$, por 10 dias antes e depois de cada dose, caso seja possível. Pacientes em tratamento com rituximab intravenoso ou com pulsoterapia intravenosa mensal com ciclofosfamida deverão ser vacinados um mês antes do começo da terapia ou 6 a 8 meses após a última dose de rituximab; em caso de pacientes em terapia anticitocina, a imunização deve ser feita 7 dias após os níveis séricos do medicamento retornarem aos valores basais; e, caso haja relutância do paciente em suspender o tratamento, esses devem ser imunizados sem suspender a terapia imunossupressora e/ ou imunorreguladora (MOUTSOPOULOS HM, 2021).

Conclui-se que, os portadores com DRIM deveriam ser priorizados para a vacinação antes da população geral. Contudo, foi observada uma importante heterogeneidade entre as condições, de tal forma que, por exemplo, um paciente portador de artrite reumatóide com doença tratada apenas com HCQ provavelmente terá um risco menor para a doença em comparação à um paciente com vasculite demasiadamente ativa tratada com ciclofosfamida ou RTX intravenoso e glicocorticóides de alta dose, embora a proteção assegurada pela vacinação também possa oscilar de acordo com a condição imunológica individual de cada paciente (CURTIS JR, et al., 2021).

Não foram encontradas contraindicações adicionais à vacinação, exceto em caso de alergias previamente conhecidas aos componentes da vacina, conforme orientado pelo Centers for Disease Control and Prevention (CDC) (CURTIS JR, et al., 2021).

Até o momento, não há comprovada correlação imunológica de proteção contra o SARS-CoV-2 após infecção natural ou exposição viral. Alguns exames sorológicos disponíveis para o SARS-CoV-2 não detectam respostas de anticorpos à proteína spike gerada pelas vacinas de RNAm, mas medem anticorpos à proteína $\mathrm{N}$ (núcleocapsídeo). Portanto, não é recomendada a realizasção de testes laboratoriais para avaliar a necessidade de vacinação em uma pessoa não vacinada ou avaliar a imunidade ao vírus após a vacinação (CURTIS JR, et al., 2021).

O Quadro 1 sumariza as principais entidades internacionais, incluindo ACR, EULAR, Canadian Rheumatology Association (CRA) e British Society for Rheumatology (BRS) e CDC reunindo as recomendações das mesmas acerca da vacinação contra SARS-CoV-2 baseada em cenários para pacientes com DRIM combinadas com recomendações acerca da suspeita ou confirmação de infecção por COVID-19 (SBR, 2021d; BATIBAY S, et al., 2021; CURTIS JR, et al., 2021). 
Quadro 1 - Sumário das Recomendações das Principais Entidades Internacionais.

\begin{tabular}{|c|c|c|c|c|}
\hline RECOMENDAÇOES & \begin{tabular}{|c|c|} 
ACR & EULAR \\
\end{tabular} & CDC & CRA & BSR \\
\hline $\begin{array}{l}\text { Plataforma vacinal preferencial } \\
\text { nos pacientes com DRIM }\end{array}$ & Não define plataforma para uso preferencial. & $\begin{array}{l}\text { Recomendam que os pacientes portadores de } \\
\text { DRIM recebam qualquer uma das vacinas de } \\
\text { RNAm disponíveis. }\end{array}$ & \multicolumn{2}{|c|}{$\begin{array}{l}\text { Não define plataforma para uso } \\
\text { preferencial. }\end{array}$} \\
\hline $\begin{array}{l}\text { Vacinar preferencialmente com } \\
\text { a doença controlada e em baixo } \\
\text { grau de imunossupressão }\end{array}$ & \multicolumn{4}{|c|}{ Sim } \\
\hline $\begin{array}{l}\text { Reduzir ou espaçar as doses } \\
\text { dos imunossupressores, nos } \\
\text { pacientes com a doença ativa }\end{array}$ & \multicolumn{4}{|c|}{ Não } \\
\hline $\begin{array}{c}\text { Considerar redução ou } \\
\text { espaçamento de dose em } \\
\text { pacientes com doença } \\
\text { controlada }\end{array}$ & \multicolumn{3}{|c|}{ Não definido } & $\begin{array}{l}\text { Não interromper o } \\
\text { tratamento }\end{array}$ \\
\hline $\begin{array}{c}\text { Decisão de vacinar deve ser } \\
\text { compartilhada entre o paciente } \\
\text { e o médico }\end{array}$ & \multicolumn{4}{|c|}{ Sim } \\
\hline Hidroxicloroquina & $\begin{array}{l}\text { Nenhuma modificação para a terapia } \\
\text { imunomoduladora ou intervalo para a vacinação } \\
\text { Independente da gravidade da infeção viral o } \\
\text { tratamento com HCQ pode ser continuado. }\end{array}$ & \multirow{2}{*}{\multicolumn{3}{|c|}{ Nenhuma modificação proposta }} \\
\hline Sulfassalazina & $\begin{array}{l}\text { Deve ser suspensa ou retida em casos de } \\
\text { suspeita ou confirmação de infecção por COVID- } \\
\text { 19, a fim de evitar o agravamento da doença } \\
\text { Nenhuma modificação para a terapia } \\
\text { imunomoduladora ou intervalo para a vacinação. }\end{array}$ & & & \\
\hline Prednisona $<20$ mg/dia & $\begin{array}{l}\text { Nenhuma modificação para a terapia } \\
\text { imunomoduladora ou intervalo para a vacinação. }\end{array}$ & & & \\
\hline Prednisona $>20 \mathrm{mg} / \mathrm{dia}$ & Não foi alcançado consenso. & & & \\
\hline $\begin{array}{l}\text { Leflunomida, azatioprina, } \\
\text { ciclosporina, tacrolimus e } \\
\text { ciclofosfamida oral }\end{array}$ & $\begin{array}{l}\text { Nenhuma modificação para a terapia } \\
\text { imunomoduladora ou intervalo para a vacinação. }\end{array}$ & $\begin{array}{l}\text { Portadores de DRIM que contraíram a infecção } \\
\text { por SARS-CoV-2 entre a primeira e a segunda } \\
\text { dose não devem adiar o término do esquema } \\
\text { vacinal. }\end{array}$ & \multicolumn{2}{|c|}{ Nenhuma modificação proposta. } \\
\hline $\begin{array}{l}\text { Anti-TNF, Anti-IL-6, Anti-IL-17, } \\
\text { Anti-IL-12/23 e Belimumabe }\end{array}$ & \multicolumn{2}{|l|}{ Nenhuma modificação proposta. } & & $\begin{array}{l}\text { Pacientes com alergia ao } \\
\text { PEG (CZP) não devem } \\
\text { receber o imunizante da } \\
\text { Pfizer/BioNtech. }\end{array}$ \\
\hline Micofenolato & $\begin{array}{l}\text { Suspender por uma semana após cada dose da } \\
\text { vacina. }\end{array}$ & Nenhuma modificação proposta. & \multicolumn{2}{|c|}{ Nenhuma modificação proposta. } \\
\hline
\end{tabular}




\begin{tabular}{|c|c|c|c|c|}
\hline RECOMENDAÇOES & EULAR & CDC & CRA & BSR \\
\hline Metrotrexato & $\begin{array}{l}\text { Suspender por uma semana após cada dose da } \\
\text { vacina ou por duas semanas após a vacinação } \\
\text { de dose única. } \\
\text { Deve ser suspenso ou retido em casos de } \\
\text { suspeita ou confirmação de infecção por COVID- } \\
\text { 19, a fim de evitar o agravamento da doença. }\end{array}$ & $\begin{array}{l}\text { Suspender por uma semana após cada dose } \\
\text { da vacina ou por duas semanas após a } \\
\text { vacinação de dose única. }\end{array}$ & & \\
\hline IJJAK & $\begin{array}{l}\text { Suspender por uma semana após cada dose da } \\
\text { vacina. } \\
\text { Deve ser suspenso ou retido em casos de } \\
\text { suspeita ou confirmação de infecção por COVID- } \\
\text { 19, a fim de evitar o agravamento da doença. }\end{array}$ & $\begin{array}{l}\text { Suspender por uma semana após cada dose } \\
\text { da vacina. }\end{array}$ & & \\
\hline Abatacepte SC & $\begin{array}{l}\text { Suspender uma semana antes e uma semana } \\
\text { após a primeira dose, sem modificações em } \\
\text { relação a segunda dose. }\end{array}$ & $\begin{array}{l}\text { Deve ser retido por uma semana antes e } \\
\text { depois da primeira dose da vacina, mas não é } \\
\text { recomendado ser retido para a segunda dose } \\
\text { e portanto, também se aplicaria a doses } \\
\text { posteriores de reforço de vacina. }\end{array}$ & & \\
\hline Abatacepte IV & $\begin{array}{l}\text { Programar a vacinação para } 4 \text { semanas após a } \\
\text { última infusão e adiar a infusão subsequente por } \\
\text { no mínimo uma semana após a imunização. }\end{array}$ & \multirow{2}{*}{\multicolumn{3}{|c|}{ Nenhuma modificação proposta. }} \\
\hline Ciclofosfamida IV & $\begin{array}{l}\text { Adiar a dose por uma semana após cada dose } \\
\text { da vacina. }\end{array}$ & & & \\
\hline Rituximabe & \multicolumn{2}{|c|}{$\begin{array}{l}\text { Programar a vacinação para } 4 \text { semanas antes do próximo ciclo, adiando a próxima dose em } 2 \text { a } 4 \\
\text { semanas após a última dose do imunizante. }\end{array}$} & $\begin{array}{l}\text { Vacinação após } \\
\text { seis meses da } \\
\text { última infusão. }\end{array}$ & $\begin{array}{l}\text { Adiar a infusão em } \\
\text { suas semanas } \\
\text { após a segunda } \\
\text { dose da vacina. } \\
\text { Utilizar o menor } \\
\text { intervalo possível } \\
\text { entre as duas } \\
\text { doses } \\
\text { imunizante. }\end{array}$ \\
\hline Paracetamol e AINES & Suspender $24 \mathrm{~h}$ antes da vacinação. & $\begin{array}{l}\text { Não recomendou a profilaxia de sintomas pós- } \\
\text { vacinais com AINEs, entretanto, não foi } \\
\text { proibido seu uso para pacientes que } \\
\text { apresentem sintomas locais ou sistêmicos pós- } \\
\text { vacinação. }\end{array}$ & \multicolumn{2}{|c|}{ Nenhuma modificação proposta. } \\
\hline
\end{tabular}

Legenda: PEG: polietilenoglicol; CZP: certolizumabe pegol; iJAK: inibidor de Janus Kinase; TNF: fator de necrose tumoral; IL: interleucina; SC: subcutâneo; IV: intravenoso. Fonte: Castro LFSO, et al., 2022; baseado em: Sociedade Brasileira de Reumatologia, 2021d; Curtis JR, et al., 2021; Batibay S, et al., 2021.

REAS | Vol.15(2) | DOI: https://doi.org/10.25248/REAS.e9855.2022 Página $\mathbf{8}$ de $\mathbf{1 0}$


Em outra diretriz recentemente publicada pela SBR baseada em cenários compostos por pacientes com DRIM a fim de auxiliar reumatologistas na decisão sobre a vacinação, sintetiza alguns pontos importantes para portadores de DRIM: (1) recomenda-se adiar a vacinação em pacientes com quadro clínico sugestivo de infecção ativa, a fim de evitar elaboração de diagnósticos diferenciais até total recuperação clínica e ao menos quatro semanas após início dos sintomas ou primeira amostra positiva de PCR, se assintomáticos; (2) Se em uso de imunoglobulina humana respeitar ao menos um mês de intervalo entre a administração dessa e da vacina a fim de não interferir na resposta imunológica do indivíduo (SBR, 2021c).

\section{CONSIDERAÇÕES FINAIS}

A COVID-19 gerou uma mobilização global da comunidade médica e científica a fim de elucidar questões clínicas e repercussões farmacológicas dessa infecção viral. Esta condição determina certo desafio para profissionais e pacientes reumatológicos visto que infecções graves são causa de mortalidade em diversas condições reumáticas devido ao estado de hiperinflamação viral associado à desregulação imunológica da enfermidade em curso. Dessa forma, apesar dos esforços realizados, a literatura ainda não foi capaz de elucidar a fisiopatologia e a repercussão humoral e celular do SARS-CoV-2 em pacientes portadores de doenças reumatológicas e, baseado nesta revisão, novas pesquisas e ensaios clínicos robustos são necessários para instruir o paciente em uso de imunossupressores e moduladores a fim de otimizar a resposta à vacina e garantir segurança e resolubilidade da doença aos pacientes portadores de doenças reumáticas.

\section{REFERÊNCIAS}

1. AQUINO EML, et al. Medidas de distanciamento social no controle da pandemia de COVID-19: potenciais impactos e desafios no Brasil. Ciência \& Saúde Coletiva, 2020; 25: 2423.

2. BATIBAY S, et al. Clinical outcomes of Covid-19 in patients with rheumatic diseases and the effects of the pandemic on rheumatology outpatient care: A single-centre experience from Turkey. International Journal of Clinical Practice, 2021: e14442.

3. BESSIÈR F, et al. Assessment of QT Intervals in a Case Series of Patients With Coronavirus Disease 2019 (COVID19) Infection Treated With Hydroxychloroquine Alone or in Combination With Azithromycin in an Intensive Care Unit. JAMA cardiology, 2020; 5(9): 1067-1069.

4. BRAZÃO SC, et al. Effects of Chloroquine and Hydroxychloroquine on the Cardiovascular System - Limitations for Use in the Treatment of COVID-19. International Journal of Cardiovascular Sciences, 2021; 34: 211-222.

5. CAVALCANTI AB, et al. Hydroxychloroquine with or without azithromycin in mild-to-moderate covid-19. New England Journal of Medicine, 2020; 383(21): 2041.

6. CENTERS FOR DISEASE CONTROL AND PREVENTION (CDC). How to protect yourself \& others. Covid-19 and your health. 2021. Acessado em: 25 de julho de 2021.

7. CHENG C, et al. COVID-19 with rheumatic diseases: a report of 5 cases. Clinical Rheumatology, 2020; 39(7): 20252029.

8. CONNOLLY CM, et al. Absence of Humoral Response After Two-Dose SARS-CoV-2 Messenger RNA Vaccination in Patients With Rheumatic and Musculoskeletal Diseases: A Case Series. Annals of Internal Medicine, 2021; M21-1451.

9. CORRÊA MCDV, et al. Controvérsias em torno do uso experimental da cloroquina / hidroxicloroquina contra a Covid19: "no magic bullet". Physis: Revista de Saúde Coletiva, 2020; 30: e300217.

10. CURTIS JR, et al. American College of Rheumatology Guidance for COVID-19 Vaccination in Patients With Rheumatic and Musculoskeletal Diseases: Version 1. Arthritis \& Rheumatology, 2021; 73(7): 1093-1107.

11. FITZGERALD GE, et al. COVID-19: What Do Rheumatologists Need to Know?. Current Rheumatology Reports, 2021; 23(1): 5 .

12. GOLDMAN JD, et al. COVID-19 in Immunocompromised Populations: Implications for Prognosis and Repurposing of Immunotherapies. Journal for ImmunoTherapy of Cancer, 2021; 9(6): e002630.

13. LADANI AP, et al. Managing rheumatic diseases during COVID-19. Clinical Rheumatology, 2020; 39(11): 3245-3254.

14. LEBEAUX D, REVEST M. No evidence of clinical benefits of early treatment of COVID-19 patients with hydroxychloroquine and azithromycin. Travel Medicine and Infectious Disease, 2020; 36: 101819.

15. MARQUES CDL, et al. High levels of immunosuppression are related to unfavourable outcomes in hospitalised patients with rheumatic diseases and COVID-19: first results of ReumaCoV Brasil registry. RMD open, 2021; 7(1): e001461.

16. MERCURO NJ, et al. Risk of QT Interval Prolongation Associated With Use of Hydroxychloroquine With or Without Concomitant Azithromycin Among Hospitalized Patients Testing Positive for Coronavirus Disease 2019 (COVID-19). JAMA Cardiol, 2020; 5(9): 1036-41. 
17. MISRA DP, et al. Rheumatologists' perspective on coronavirus disease 19 (COVID-19) and potential therapeutic targets. Clinical Rheumatology, 2020; 39(7): 2055-2062.

18. MITJÀ O, et al. A cluster-randomized trial of hydroxychloroquine for prevention of covid-19. New England Journal of Medicine. 2021; 384(5): 417-27.

19. MOUTSOPOULOS HM. A Recommended Paradigm for Vaccination of Rheumatic Disease Patients with the SARSCoV-2 Vaccine. Journal of Autoimmunity, 2021; 121: 102649.

20. THE RECOVERY COLLABORATIVE GROUP, et al. Effect of Hydroxychloroquine in Hospitalized Patients with Covid19. The New England Journal of Medicine, 2020;383(21)2030-2040.

21. SOCIEDADE BRASILEIRA DE REUMATOLOGIA (SBR). Força-Tarefa para Gerar as Orientações de Vacinação contra SARS-CoV-2 para Pacientes com Doenças Reumáticas Imunomediadas (DRIM). 2021. Acessado em 16 de julho de 2021.

22. SOCIEDADE BRASILEIRA DE REUMATOLOGIA (SBR). Nota de Esclarecimento da SBR sobre Imunização contra COVID-19 em Pacientes de Doenças Reumáticas. 2021. Acessado em: 14 de julho de 2021.

23. SOCIEDADE BRASILEIRA DE REUMATOLOGIA (SBR). Primeira atualização das Orientações para Reumatologistas Acerca da Vacinação Contra SARSCoV-2 Baseada em Cenários, em Pacientes com Doenças Reumáticas Imunomediadas (DRIM). 2021. Acessado em: 15 de julho de 2021.

24. SOCIEDADE BRASILEIRA DE REUMATOLOGIA (SBR). Segunda Atualização das Orientações para Reumatologistas acerca da Vacinação contra SARS-CoV-2 Baseada em Cenários para Pacientes com Doenças Reumáticas Imunomediadas (DRIM). 2021. Acessado em: 25 de julho de 2021.

25. STRANGFELD A, et al. Factors associated with COVID-19-related death in people with rheumatic diseases: results from the COVID-19 Global Rheumatology Alliance physician-reported registry. Annals of the Rheumatic Diseases, 2021.

26. WANG Q, et al. Risk and clinical outcomes of COVID-19 in patients with rheumatic diseases compared with the general population: a systematic review and meta-analysis. Rheumatology International, 2021; 41(5): 851-861.

27. ZHU N, et al. A Novel Coronavirus from Patients with Pneumonia in China, 2019. The New England Journal of Medicine, 2020; 382(8): 727-733. 